Received: 4 May 2018

Accepted: 28 December 2018

Published online: 14 February 2019

\section{Litter removal reduced soil nitrogen mineralization in repeated freeze- thaw cycles}

\author{
Yulian Yang ${ }^{1,2}$, Li Zhang ${ }^{1}$, Xinyu Wei ${ }^{1}$, Ya Chen ${ }^{1}$, Wanqin Yang ${ }^{1}$, Bo Tan ${ }^{1}$, KaiYue $\mathbb{B}^{1}$, \\ Xiangyin $\mathrm{Ni} \mathbb{D}^{1}$ \& Fuzhong Wu $\mathbb{B}^{1}$
}

Repeated freeze-thaw cycles (FTCs) can alter the relationships between plant litter and soil nitrogen (N) mineralization in subalpine ecosystems, but little information is available about the underlying mechanisms. Therefore, a controlled soil incubation experiment was carried out to study the effects of litter removal on soil N mineralization during FTCs, and the results indicated that FTCs promoted soil N mineralization more than the continuously frozen or nonfrozen condition did. Litter removal promoted soil ammonium $\mathrm{N}\left(\mathrm{NH}_{4}{ }_{-}-\mathrm{N}\right)$ and dissolved organic $\mathrm{N}(\mathrm{DON})$ as well as the cumulative $\mathrm{N}$ mineralization (CNM) and ammonification, but it reduced the soil microbial biomass $N$ (MBN) in the early stage of FTCs. With an increasing number of FTCs, litter removal significantly reduced the CNM but increased the soil MBN. The modified first-order kinetics model was verified under incubation conditions and predicted a lower soil $\mathrm{N}$ mineralization rate in FTCs with litter removal. In addition, the dominant factor impacting soil $\mathrm{N}$ mineralization was soil $\mathrm{NO}_{3}{ }^{-}-\mathrm{N}$, and soil $\mathrm{MBN}$ had a greater influence on soil $\mathrm{N}$ mineralization when litter remained than when it was removed. These results further clarify the mechanism driving the effect of plant residues on soil $\mathrm{N}$ cycling.

Soil nitrogen $(\mathrm{N})$ mineralization, which regulates $\mathrm{N}$ availability and supply, is a key process in forest ecosystems $^{1-4}$. Although soil $\mathrm{N}$ is mainly formed through the partial decomposition and transformation of plant residues $^{3,5,6}$, the rate of $\mathrm{N}$ transformation in the soil is closely linked to litter quality ${ }^{7-9}$ and climate factors ${ }^{10-12}$. Previous studies have shown that carbon $(\mathrm{C})$ and nutrients from the decomposition of plant residues can provide adequate energy and nutrients for the growth of soil microorganisms $\mathrm{s}^{13,14}$ and that increased microorganism quantity and activity ${ }^{15}$ accelerate soil $\mathrm{N}$ mineralization. Furthermore, microorganisms can improve $\mathrm{N}$ availability by immobilizing mineralized mineral $\mathrm{N}$ within their cells ${ }^{14}$ and can even retain most immobilized organic $\mathrm{N}$ in $\mathrm{N}$-limited soil environments, both of which result in low $\mathrm{N}$ mineralization ${ }^{16}$. In addition, altered microbial community compositions in response to plant residue input ${ }^{14,17}$ may clearly affect microbial $\mathrm{N}$-use efficiency ${ }^{18}$; in turn, these alterations affect the $\mathrm{N}$ mineralization process. However, the relationship between litter and soil $\mathrm{N}$ mineralization is unclear, so knowledge of how plant residue inputs affect both the soil $\mathrm{N}$ mineralization process and its influencing factors could significantly contribute to our understanding of nutrient cycling, especially that of $\mathrm{N}$ in forest ecosystems.

Freeze-thaw cycles (FTCs) in soils are common phenomenon in high-altitude and high-latitude regions as well as some temperate zones ${ }^{10,11}$, and they may affect soil $\mathrm{N}$ mineralization when litter is deposited in subalpine forests. FTCs break down soil aggregates, thereby increasing the availability of soil $\mathrm{N}$ to soil microorganisms via exchange across the resulting increased surface area ${ }^{11}$, and repeated FTCs can promote microorganism cell destruction and stimulate the metabolism of surviving microorganisms via their internal release of $\mathrm{C}$ and $\mathrm{N}$ in the soil ${ }^{10,11,19,20}$. Mechanical fragmentation also stimulates the release of $\mathrm{C}$ and nutrients from decomposing plant residue $^{13,21-23}$, thereby increasing microbial activity and $\mathrm{N}$ immobilization ${ }^{9}$. Additionally, although a relatively high fungi/bacteria ratio has been reported when litter is input into a system ${ }^{17,24}$, substantially reduced amounts of fungi and stable amounts of bacteria due to $\mathrm{FTC}^{25}$ may impact soil microorganism community structure, affect microbial $\mathrm{N}$-use efficiency, and further alter organic $\mathrm{N}$ decomposition and immobilization processes ${ }^{23}$.

${ }^{1}$ Long-Term Research Station of Alpine Forest Ecosystems, Key Laboratory of Ecological Forestry Engineering, Institute of Ecology and Forestry, Sichuan Agricultural University, Chengdu, 611130, China. ${ }^{2}$ Ecological Security and Protection Key Laboratory of Sichuan Province, Mianyang Normal University, Mianyang, 621000, China. Correspondence and requests for materials should be addressed to F.W. (email: wufzchina@163.com) 
$\circ$ frozen - FTC $\triangle$ nonfrozen
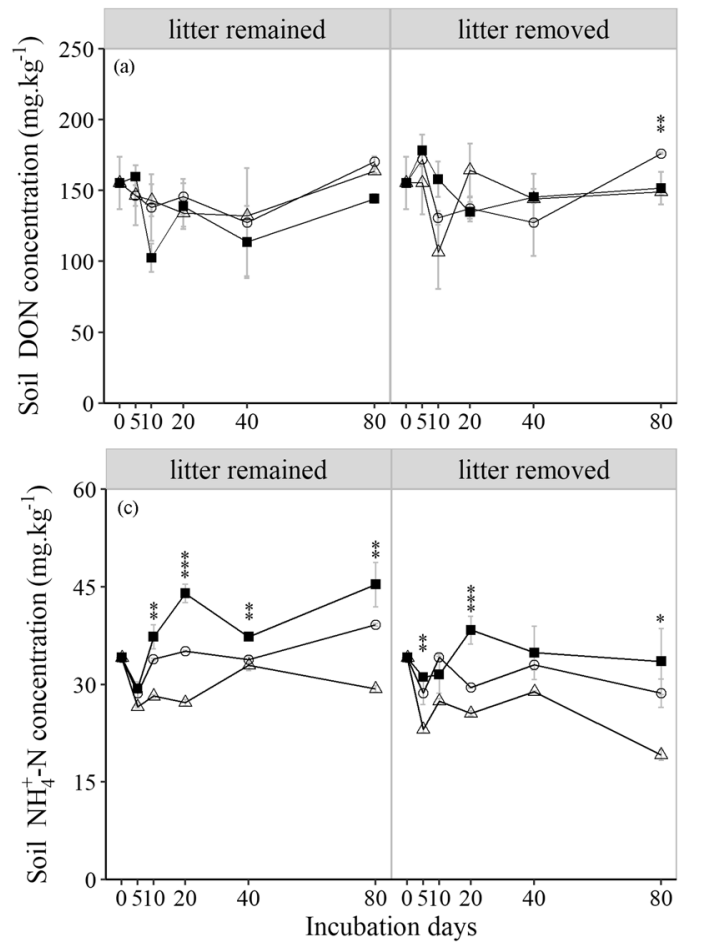

$\circ$ frozen - FTC $\triangle$ nonfrozen
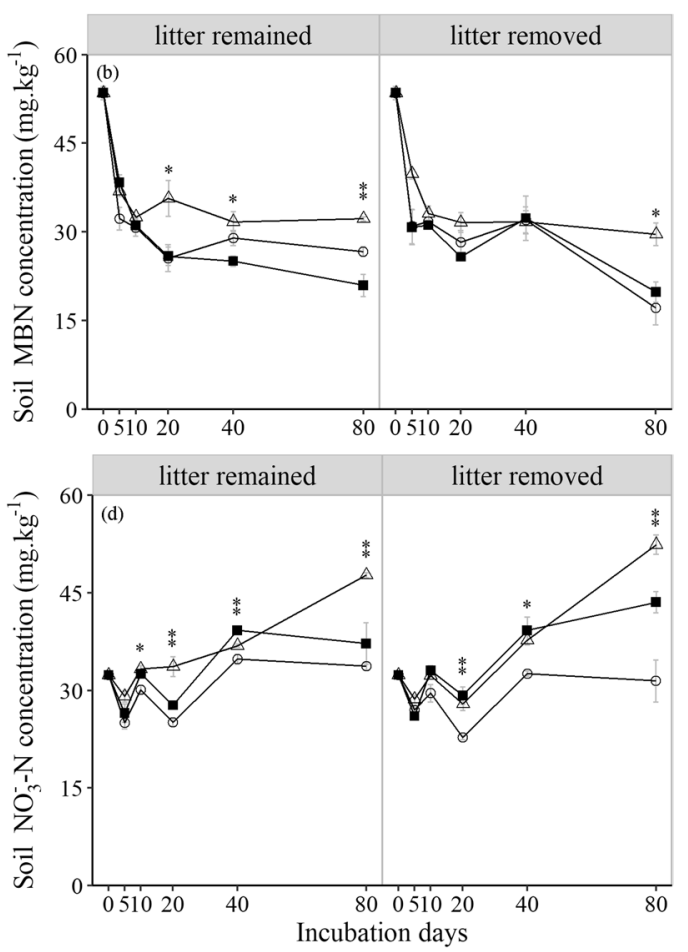

Figure 1. The dynamics of soil nitrogen $(\mathrm{N})$ pools varied with litter and freeze-thaw treatments (mean $\pm \mathrm{SE}$, $\mathrm{n}=3$ ). *Denotes a significant difference between different freeze-thaw treatments for the same litter treatments and incubation days. *Indicates $P<0.05$; **indicates $P<0.01$; and ***indicates $P<0.001$.

Ongoing global climate warming has been altering the intensity, frequency and duration of FTCs through milder winters and thinner snow cover ${ }^{10,26}$, which may strongly affect soil structure, soil microorganism activity and soil microorganism communities ${ }^{27-29}$ and therefore alter the relationship between litter and soil $\mathrm{N}$ mineralization. To date, the individual effects of plant residue inputs and FTCs as well as their comprehensive effects on soil $\mathrm{N}$ mineralization are uncertain and urgently need to be elucidated. We hypothesized that litter removal would reduce soil $\mathrm{N}$ mineralization under repeated FTCs because more $\mathrm{C}$ and nutrient sources would be available from plant residue decomposition, although the soil N pools would differ with various FTC frequencies.

To test this hypothesis, a controlled soil incubation experiment to simulate freeze-thaw conditions was conducted using subalpine forest soils collected from a typical subalpine forest in the upper reaches of the Yangtze River, China. Soil N pool and $\mathrm{N}$ flux dynamics were determined and compared to understand the response of soil $\mathrm{N}$ mineralization to litter and freeze-thaw patterns. We specifically focused on the following research questions: (1) Do soil N pools and N fluxes decrease in response to litter removal under FTC conditions? (2) How do FTC regimens (e.g., frequency and duration) influence $\mathrm{N}$ pools and fluxes when plant residues are removed? The answers to these questions will provide basic data on the effects of the interaction between litter and FTCs on soil $\mathrm{N}$ cycling in subalpine forest ecosystems and will further help to clarify the underlying mechanism.

\section{Results}

Soil N pool dynamics. The effects of litter removal on soil N pools clearly differed due to freeze-thaw patterns and incubation time (Fig. 1, Table 1). Compared with the frozen and nonfrozen treatments, the FTC treatment significantly increased the soil dissolved organic $\mathrm{N}(\mathrm{DON})$ by $54.02 \%$ and $27.93 \%$ after 10 and 40 days of incubation, respectively, when the litter was removed (Fig. 1a). The soil microbial biomass N (MBN) concentrations were lower in the FTC and frozen treatments than in the nonfrozen treatment between 10 and 80 days in the two litter treatments, and the greatest declines were $34.99 \%$ and $42.20 \%$ in the litter-remained and litter-removal treatments, respectively. In addition, compared with the frozen and nonfrozen treatments, the FTC treatment significantly reduced the soil MBN concentration by $19.7 \%$ after 5 days of incubation, whereas the soil MBN increased by $28.94 \%$ after 40 days of incubation when the litter was removed (Fig. 1b).

Regardless of whether the litter remained or was removed, compared with the nonfrozen treatment, the FTC and frozen treatments significantly increased the soil ammonium $\mathrm{N}\left(\mathrm{NH}_{4}{ }^{+}-\mathrm{N}\right)$ level by $10.54-74.82 \%$ and $0.03-$ $49.41 \%$, respectively. Soil $\mathrm{NH}_{4}{ }^{+}-\mathrm{N}$ in the FTC and frozen treatments increased in response to litter removal after 5 days of incubation, but during incubation periods of 10 to 80 days, litter removal reduced the soil $\mathrm{NH}_{4}{ }^{+}-\mathrm{N}$, with the greatest declines of $26.09 \%, 26.83 \%$, and $34.58 \%$ occurring in the FTC, frozen, and nonfrozen treat-

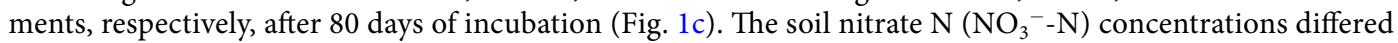
slightly among all the treatments, and the levels were lower in the frozen treatment than in the FTC or nonfrozen 


\begin{tabular}{|l|c|c|c|c|c|c|l|}
\hline Factor & DON & MBN & $\mathrm{NH}_{4}{ }^{+}-\mathbf{N}$ & $\mathrm{NO}_{3}{ }^{-}-\mathbf{N}$ & $\mathrm{CA}$ & $\mathrm{CN}$ & $\mathrm{CNM}$ \\
\hline FT & 2.66 & $182.10^{* * *}$ & $24.96^{* *}$ & $172.8^{* * *}$ & $24.96^{* *}$ & $172.8^{* * *}$ & $16.11^{*}$ \\
\hline $\mathrm{L}$ & $20.16^{*}$ & 1.27 & $48.37^{* * *}$ & 0.05 & $48.37^{* * *}$ & 0.05 & $22.45^{*}$ \\
\hline $\mathrm{D}$ & $8.36^{* *}$ & $51.30^{* * *}$ & $16.17^{* *}$ & $183.50^{* * *}$ & $16.17^{* *}$ & $183.50^{* * *}$ & $69.45^{* * *}$ \\
\hline FT $\times \mathrm{L}$ & 2.72 & 1.44 & 1.39 & $14.41^{*}$ & 1.39 & $14.41^{*}$ & 0.77 \\
\hline FT $\times \mathrm{D}$ & 0.81 & $11.01^{* * *}$ & $8.70^{* *}$ & $57.06^{* * *}$ & $8.70^{* *}$ & $57.06^{* * *}$ & $8.24^{* * *}$ \\
\hline $\mathrm{L} \times \mathrm{D}$ & 3.07 & $9.63^{* *}$ & $46.65^{* * *}$ & $10.64^{* *}$ & $46.65^{* * *}$ & $10.64^{* *}$ & $8.28^{* *}$ \\
\hline FT $\times \mathrm{L} \times \mathrm{D}$ & $8.25^{* * *}$ & $9.16^{* * *}$ & $4.78^{* *}$ & $4.04^{* *}$ & $4.78^{* *}$ & $4.04^{* *}$ & 2.18 \\
\hline
\end{tabular}

Table 1. Repeated measures ANOVA results for the responses of soil nitrogen $(\mathrm{N})$ pools and fluxes to freezethaw treatments (FT), litter treatments (L), incubation days (D) and their interactions. $* P<0.05$; $* * P<0.01$; $* * * P<0.001$.

$\circ$ frozen - FTC $\triangle$ nonfrozen
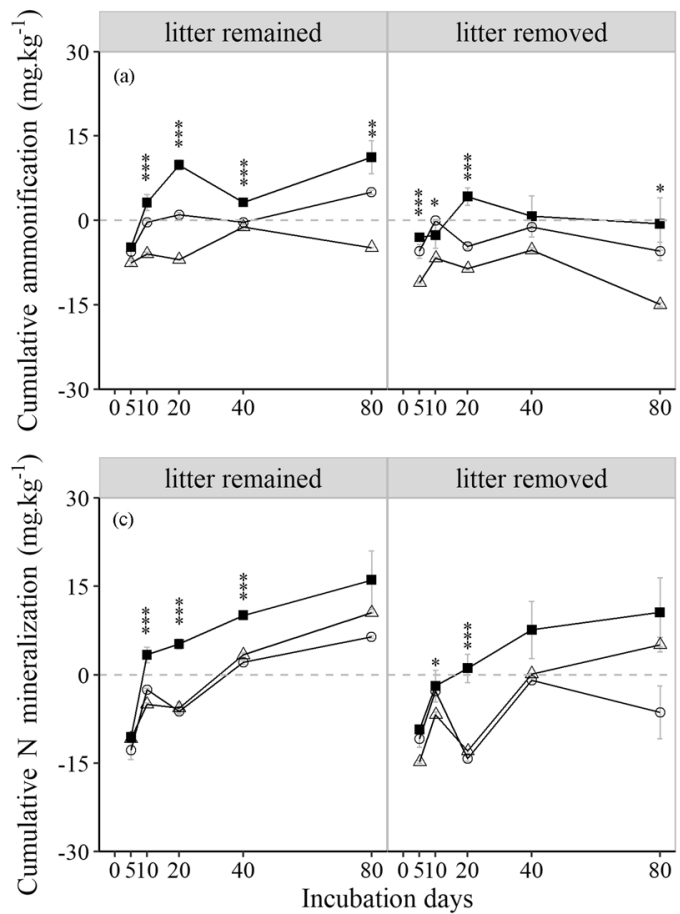

$\circ$ frozen - FTC $\triangle$ nonfrozen

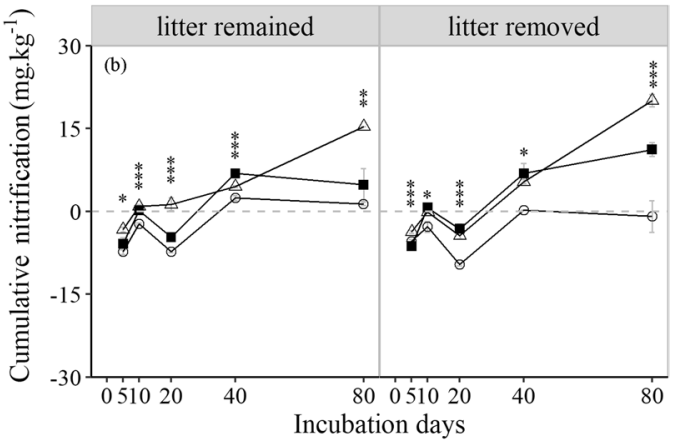

Figure 2. The soil cumulative ammonification (CA), cumulative nitrification (CN) and cumulative $\mathrm{N}$ mineralization $(\mathrm{CNM})$ dynamics varied with litter and freeze-thaw treatments (mean $\pm \mathrm{SE}, \mathrm{n}=3$ ). *Denotes a significant difference between different freeze-thaw treatments for the same litter treatments and incubation days. $* P<0.05 ; * * P<0.01 ; * * * P<0.001$.

treatment during incubation periods of 10 to 80 days. Compared with that in the frozen or nonfrozen treatment, litter removal in the FTC treatment increased soil $\mathrm{NO}_{3}{ }^{-}-\mathrm{N}$ by $5.45 \%$ and $17.10 \%$ after 20 and 80 days of incubation, respectively (Fig. 1d).

Soil $\mathbf{N}$ flux dynamics. Litter treatment, freeze-thaw treatment and their interactions had significant effects on soil $\mathrm{N}$ fluxes, but there were differences among different culture periods (Fig. 2, Table 1). In general, the soil cumulative $\mathrm{N}$ mineralization $(\mathrm{CNM})$ and cumulative nitrification $(\mathrm{CN})$ in the FTC treatment increased as the incubation time increased, whereas the soil cumulative ammonification (CA) exhibited only a slight ascending tendency. Unlike the soil CNM in the FTC treatment, which exhibited a period of rapid increase in the early culture stage and then increased slowly, there was a downward trend in the frozen and nonfrozen treatments after 20 days of incubation (Fig. 2c). After 5 days of incubation, the soil CNM, CA, and CN values were all negative, and the $\mathrm{N}$ cycle was dominated by $\mathrm{N}$ immobilization. During the incubation period from 10 to 80 days, litter removal inhibited the soil CNM, and the AR increased in all treatments, although the FTC treatment promoted the soil CNM and AR. Most of the soil NMR, NR and AR values in the litter-remained treatment were positive, and the $\mathrm{N}$ cycle was dominated by $\mathrm{N}$ mineralization. Moreover, the duration required for the soil CNM and CA values to become positive was extended by litter removal in the FTC treatment (Fig. 2a,c). 


\begin{tabular}{|c|c|c|c|c|c|c|}
\hline \multirow[b]{2}{*}{ Treatment } & \multicolumn{3}{|l|}{ Parameter } & \multirow[b]{2}{*}{ AIC } & \multirow[b]{2}{*}{ F } & \multirow[b]{2}{*}{$P$} \\
\hline & $\mathrm{N}_{0}\left(\mathrm{mg} \mathrm{kg}^{-1}\right)$ & $\mathrm{N}_{\mathrm{e}}\left(\mathrm{mg} \mathrm{kg}^{-1}\right)$ & $\mathbf{k}\left(\right.$ day $\left.^{-1}\right)$ & & & \\
\hline \multicolumn{7}{|c|}{ Litter remained } \\
\hline FTC & $-21.5^{\mathrm{A}}$ & $13.41^{\mathrm{A}}$ & $0.09^{\mathrm{B}}$ & 56.29 & 19.72 & $<0.001$ \\
\hline Frozen & $-13.04^{\mathrm{A}}$ & $8.29^{\mathrm{A}}$ & $0.03^{\mathrm{A}}$ & 45.29 & 18.6 & $<0.001$ \\
\hline Nonfrozen & $-12.07^{\mathrm{A}}$ & $20.28^{\mathrm{A}}$ & $0.02^{\mathrm{A}}$ & 28.54 & 75.52 & $<0.001$ \\
\hline \multicolumn{7}{|c|}{ Litter removed } \\
\hline FTC & $-14.07^{\mathrm{A}}$ & $10.73^{\mathrm{A}}$ & $0.05^{\mathrm{AB}}$ & 62.75 & 6.96 & $<0.01$ \\
\hline Frozen & not fit & not fit & not fit & not fit & not fit & not fit \\
\hline Nonfrozen & $-15.28^{\mathrm{A}}$ & $16.84^{\mathrm{A}}$ & $0.01^{\mathrm{A}}$ & 49.01 & 27.28 & $<0.001$ \\
\hline
\end{tabular}

Table 2. Parameters of the modified first-order kinetics model of nitrogen $(\mathrm{N})$ mineralization in the different treatments. The parameter values followed by the same capital letter are not significantly different between the five treatments $(P>0.05)$.

Soil $\mathbf{N}$ mineralization model. The best-fit modified first-order kinetics model obtained in the nonfrozen and litter-remained treatment emphasized the results that soil $\mathrm{N}$ mineralization progress was influenced by litter removal and soil freeze-thaw cycles (Table 2). Compared with the FTC and nonfrozen treatments, the frozen treatment reduced the contribution of the soil MBN to soil $\mathrm{N}$ mineralization with the decreased values of MBN $\left(\mathrm{N}_{\mathrm{e}}\right)$ when litter remained, whereas the model was not fit when litter was removed because of a greater number of uncertainty factors. The FTC treatment significant increased the $\mathrm{k}$ values, which were $66.67 \%$ and $77.78 \%$ higher than those of the frozen and nonfrozen treatments, respectively, when litter remained and $80.00 \%$ higher than those of the nonfrozen treatment, with litter removal. Furthermore, the $\mathrm{k}$ value was higher when litter remained than when it was removed, especially in the FTC treatment.

\section{Discussion}

In this study, different FTC regimens clearly affected soil $\mathrm{N}$ cycling in the subalpine forest, which is consistent with the results of previous studies ${ }^{10,30-32}$, in which FTCs increased soil inorganic $\mathrm{N}$ concentrations and promoted soil $\mathrm{N}$ mineralization ${ }^{10,11}$. Moreover, our hypotheses that litter removal would reduce the soil CNM and slow soil $\mathrm{N}$ mineralization and that these effects would be even greater under the FTC or frozen treatment were well supported in the present study. However, the soil DON and MBN tended to increase in response to litter removal in the FTC treatment. An understanding of soil $\mathrm{N}$ mineralization processes both when litter is removed and when the soil is subjected to FTCs is essential for explaining $\mathrm{N}$ cycling in alpine forests.

The size of the soil organic $\mathrm{N}$ pool depends on the balance between the formations of soil organic $\mathrm{N}$ from the decomposition of plant litter and its mineralization into inorganic $\mathrm{N}$ by soil organisms $\mathrm{s}^{33}$. Increases or decreases in the abundance of soil microorganisms, the drivers of $\mathrm{N}$ cycling, can directly affect the soil $\mathrm{N}$ pools and $\mathrm{N}$ fluxes in alpine forests ${ }^{10}$, and the number of microorganisms present can rapidly decrease due to partial microbial resistance to FTCs or freezing stress ${ }^{11,20,28}$. Therefore, in this study, extremely adverse environmental conditions in conjunction with no additional energy or nutrient inputs caused the soil MBN to decrease when litter was removed directly (Fig. 1b). Although nutrients from disrupted microbial cells would promote soil DON, $\mathrm{NH}_{4}{ }^{-} \mathrm{N}$ and $\mathrm{NO}_{3}{ }^{-}-\mathrm{N}^{10}$, lower microorganism activity due to limited energy and nutrients would account for the increased soil DON and $\mathrm{NH}_{4}{ }^{+}-\mathrm{N}$ when the litter was removed (Fig. 1a,c). There are two reasonable explanations for the increased MBN in response to litter removal as the number of FTCs and the continuous acquisition of nutrients in the soil increased in the FTC treatment: (1) fewer N resources increase soil MBN because microorganisms retain most of the immobilized organic $\mathrm{N}$ in their cells ${ }^{16}$, and (2) the affected groups of microorganisms also increase the soil MBN. On the one hand, substantially reduced amounts of fungi due to $\mathrm{FTCs}^{25}$ and the relatively lower fungal demand for N may directly cause MBN to decrease. On the other hand, relatively high amounts of fungi when litter remains ${ }^{18,24}$ will lead to a decrease in soil MBN. In contrast, litter removal reduced the soil $\mathrm{NH}_{4}{ }^{-} \mathrm{N}$ in the FTC treatment, although the FTCs generally increased the soil $\mathrm{NH}_{4}{ }^{+}-\mathrm{N}$, which was mainly attributable to soil microorganisms. The soil CNM and CA showed trends opposite to that of the soil MBN concentration due to regulation by microorganisms (Figs 1,2). As concurrent processes, higher microorganism $\mathrm{N}$ immobilization means lower soil $\mathrm{N}$ mineralization, thereby reducing soil $\mathrm{NH}_{4}{ }^{+}-\mathrm{N}$ levels. The significant negative relationship between soil CNM and MBN (Table 3) and the reduced soil CNM and SA (Fig. 2) in response to litter removal also verified these results. However, the effects on soil SA and SN were not consistent (Fig. 2), which was mainly due to the preference of the microorganisms to use $\mathrm{NH}_{4}{ }^{+}-\mathrm{N}$ rather than $\mathrm{NO}^{-}-\mathrm{N}^{3}$. However, heterotrophs could no longer immobilize $\mathrm{NH}_{4}{ }^{+}-\mathrm{N}$, but soil nitrifiers could still oxidize $\mathrm{NH}_{4}{ }^{+}-\mathrm{N}$ into $\mathrm{NO}_{3}{ }^{-}-\mathrm{N}$. Therefore, $\mathrm{NO}_{3}{ }^{-}-\mathrm{N}$ could accumulate when $\mathrm{C}$ substrates were unavailable ${ }^{34}$, especially during the later culture period, in response to litter removal in the absence of sufficient $\mathrm{C}$. In addition, the reduced soil CNM and CA and the inhibition of soil N mineralization by litter removal in the FTC treatment (Fig. 2) indicated the importance of litter to soil N mineralization and $\mathrm{N}$ cycling.

The progress of soil $\mathrm{N}$ mineralization and its influencing factors are very complex, and based on previous studies, it is more likely that there are at least two types of organic $\mathrm{N}$ sources with different mineralization potentials in the soil mineralized $\mathrm{N}$ pools ${ }^{35,36}$, as has been verified in alternating dry and wet environments ${ }^{37}$. Our study reached a similar conclusion, and the higher values of $\mathrm{k}$ indicate faster soil $\mathrm{N}$ mineralization rate; in addition, the negative values of $\mathrm{N}_{0}$ may due to the soil $\mathrm{N}$ mineralization-immobilization cycle process, which needs to 


\begin{tabular}{|c|c|c|c|c|c|c|c|c|}
\hline \multirow[b]{2}{*}{ Treatment } & \multicolumn{5}{|c|}{ Best regression model } & \multirow[b]{2}{*}{ AIC } & \multirow[b]{2}{*}{$\mathbf{R}_{\text {adj. }}^{2}$} & \multirow[b]{2}{*}{$P$} \\
\hline & $a_{0}$ & $a_{1} X_{1}$ & $a_{2} X_{2}$ & $a_{3} X_{3}$ & $a_{4} X_{4}$ & & & \\
\hline \multicolumn{9}{|c|}{ Litter remained } \\
\hline FTC & $y=-41.27^{* * *}$ & $0.82\left(\mathrm{NO}_{3}{ }^{-}{ }^{-} \mathrm{N}\right)^{* * *}$ & $0.76\left(\mathrm{NH}_{4}{ }^{+}-\mathrm{N}\right)^{* * * *}$ & $-0.30(\mathrm{MBN})^{* * *}$ & $-0.01(\mathrm{DON})^{*}$ & -16.94 & 0.997 & $<0.001$ \\
\hline Frozen & $y=-53.60^{* * *}$ & $1.00\left(\mathrm{NO}_{3}^{-}{ }^{-} \mathrm{N}\right)^{* * *}$ & $0.89\left(\mathrm{NH}_{4}^{+}-\mathrm{N}\right)^{* * *}$ & $-0.23(\mathrm{MBN})^{*}$ & $-0.02(\mathrm{DON})$ & 1.10 & 0.983 & $<0.001$ \\
\hline Nonfrozen & $y=-46.50^{* * *}$ & $1.05\left(\mathrm{NO}_{3}^{-}-\mathrm{N}\right)^{* * * *}$ & $0.70\left(\mathrm{NH}_{4}{ }^{+}-\mathrm{N}\right)^{* * *}$ & $-0.20(\mathrm{MBN})^{*}$ & $-0.04(\mathrm{DON})^{*}$ & -1.15 & 0.988 & $<0.001$ \\
\hline \multicolumn{9}{|c|}{ Litter removed } \\
\hline FTC & $y=-50.83^{* * *}$ & $0.95\left(\mathrm{NO}_{3}{ }^{-}-\mathrm{N}\right)^{* * *}$ & $0.79\left(\mathrm{NH}_{4}^{+}-\mathrm{N}\right)^{* * *}$ & $-0.04(\mathrm{MBN})$ & $-0.04(\mathrm{DON})^{* *}$ & -8.05 & 0.993 & $<0.001$ \\
\hline Frozen & $y=-50.58^{* * *}$ & $1.06\left(\mathrm{NO}_{3}{ }^{-}-\mathrm{N}\right)^{* * *}$ & $0.61\left(\mathrm{NH}_{4}{ }^{+}-\mathrm{N}\right)^{* * *}$ & $-0.04(\mathrm{DON})^{* *}$ & & -0.06 & 0.973 & $<0.001$ \\
\hline Nonfrozen & $y=-48.46^{* * *}$ & $0.90\left(\mathrm{NO}_{3}{ }^{-}-\mathrm{N}\right)^{* * *}$ & $0.80\left(\mathrm{NH}_{4}{ }^{+}-\mathrm{N}\right)^{* * *}$ & $-0.19(\mathrm{MBN})^{* *}$ & $-0.02(\mathrm{DON})^{* * * *}$ & -3.70 & 0.990 & $<0.001$ \\
\hline
\end{tabular}

Table 3. Regression model of soil cumulative nitrogen $(\mathrm{N})$ mineralization and factors under different treatments. $* P<0.05 ; * * P<0.01 ; * * * P<0.001$

\begin{tabular}{|l|l|l|l|l|l|l|l|l|}
\hline & $\begin{array}{l}\mathbf{O C} \\
\left(\mathbf{g ~ k g}^{-1}\right)\end{array}$ & $\begin{array}{l}\text { TN } \\
\left(\mathbf{g ~ k g}^{-1}\right)\end{array}$ & $\begin{array}{l}\text { TP } \\
\left(\mathbf{g ~ k g}^{-1}\right)\end{array}$ & $\mathbf{C} / \mathbf{N}$ & $\mathbf{C} / \mathbf{P}$ & $\begin{array}{l}\text { WHC } \\
\left(\mathbf{k g ~ k g}^{-1}\right)\end{array}$ & $\begin{array}{l}\mathbf{B} \\
\left(\mathbf{g ~ c m}^{-3}\right)\end{array}$ & $\mathbf{p H}$ \\
\hline Soil & $57.77 \pm 2.63$ & $3.88 \pm 0.16$ & $1.18 \pm 0.04$ & $14.92 \pm 1.23$ & $48.96 \pm 3.70$ & $1.23 \pm 0.02$ & $0.74 \pm 0.11$ & $5.42 \pm 0.05$ \\
\hline Litter & $348.00 \pm 6.10$ & $2.23 \pm 0.03$ & $0.76 \pm 0.02$ & $155.79 \pm 5.03$ & $456.76 \pm 14.37$ & $/$ & $/$ & $/$ \\
\hline
\end{tabular}

Table 4. Basic physical and chemical properties of the soil and litter (mean $\pm S E, n=3$ ). OC, Organic carbon; TN, Total nitrogen; TP, Total phosphorus; WHC, Water-holding capacity; BD, Bulk density.

be studied further to reveal the $\mathrm{N}$ mechanism model. A previous study considered $\mathrm{N}_{\mathrm{e}}$ a small source of easily mineralized $\mathrm{N}$ that would be exhausted within a week ${ }^{37}$; however, the little differences from $\mathrm{N}_{0}$ in our results are possibly due to the adaptation of soil microorganisms to the freeze-thaw environment of alpine forests. Moreover, our regression results also verified soil MBN as a significant factor influencing soil CNM when litter remained (Table 3). In contrast, soil microbial activity may be altered little when there is no extra energy or nutrient input to the soil environment under the disturbance of the soil environment by $\mathrm{FTC}_{S}$, so soil $\mathrm{MBN}$ did not significantly affect soil CNM in the FTC and frozen treatments (Table 3). In a word, differences in key impact indicators between the litter-remained and litter-removal treatments also indicate different mechanisms of soil $\mathrm{N}$ conversion (Tables 2 and 3). Moreover, reduced amounts of soil microbes would decrease the gross mineralization under FTC conditions, but decreased immobilization of $\mathrm{NH}_{4}{ }^{+}-\mathrm{N}$ and $\mathrm{NO}_{3}{ }^{-}-\mathrm{N}$ by soil microorganisms and the adaptation of microorganisms to long-term FTCs would counterbalance these effects ${ }^{10}$, causing the interactions among freeze-thaw patterns, litter treatment and incubation time to have no significant impact on the soil CNM (Table 1).

\section{Conclusions}

In summary, altered FTC regimens due to ongoing global climate can change the relationships between plant litter and soil $\mathrm{N}$ mineralization in subalpine ecosystems, but these changes are controlled by the frequency or duration of the FTCs. In the early stage of FTCs, litter removal increased soil $\mathrm{NH}_{4}{ }^{+}-\mathrm{N}, \mathrm{DON}, \mathrm{CNM}$ and CA but reduced soil MBN. In contrast, litter removal decreased soil $\mathrm{NH}_{4}{ }^{+}-\mathrm{N}, \mathrm{NO}_{3}{ }^{-}-\mathrm{N}, \mathrm{CNM}$ and CA but increased soil MBN and the $\mathrm{CN}$ in the later stage. In conjunction with remaining litter, the FTCs clearly promoted the soil CNM. In addition, the most important factor that impacted soil $\mathrm{N}$ mineralization was soil $\mathrm{NO}_{3}{ }^{-}-\mathrm{N}$, and soil $\mathrm{MBN}$ influenced soil $\mathrm{N}$ mineralization more strongly when the litter remained than when it was removed. These findings confirmed that plant residue inputs promote $\mathrm{N}$ mineralization under frequent FTCs, and the results of this study will facilitate the elucidation of the mechanism underlying the effects of plant residues on soil $\mathrm{N}$ cycles.

\section{Materials and Methods}

Experimental design. In May 2017, samples of both soils from the organic layer $(0-15 \mathrm{~cm})$ and undecomposed litter on the soil surface were randomly collected from three Picea purpurea forest sites with similar elevations and age structures. The forests are located in the Wanglang National Nature Reserve, Sichuan Province, China $\left(103^{\circ} 55^{\prime}-104^{\circ} 10^{\prime} \mathrm{E}, 32^{\circ} 49^{\prime}-33^{\circ} 02^{\prime} \mathrm{N}\right)$ on the eastern Qinghai-Tibetan Plateau at an altitude of $2300-$ $4980 \mathrm{~m}$, and the freeze-thaw season generally extends from late October to late April of the following year. The mean annual temperature ranges from 2.5 to $2.9^{\circ} \mathrm{C}$, and the maximum and minimum monthly means are $12.7^{\circ} \mathrm{C}$ and $-6.1^{\circ} \mathrm{C}$ in July and January, respectively ${ }^{38}$. The annual precipitation ranges from 801 to $825 \mathrm{~mm}$ depending on the elevation, with most falling between May and August ${ }^{39}$. The dominant trees are P. purpurea, Abies faxoniana, Sabina saltuaria, Betula albosinensis, and Betula utilis, and the dominant shrubs are Salix cupularis, Fargesia denudata and Elaeagnus pungens. The soil type of the P. purpurea forest is a dark brown forest soil according to the Chinese soil genetic classification ${ }^{40}$ and is classified as a type of Cambisol in other classification systems ${ }^{41}$. The physical and chemical properties of the soil are listed in Table 4.

After they were passed through a 2-mm sieve to remove roots and gravel, well-mixed soil samples ( $250 \mathrm{~g})$ were placed into 350-ml gas-permeable polyethylene tanks, brought to a surface area of $50.24 \mathrm{~cm}^{2}$ and wetted to $60 \%$ of their water-holding capacity. The samples were then incubated at $5^{\circ} \mathrm{C}$ for three days to increase the tendency of the soil to remain stable after disturbance. The leaf litter was air-dried for two weeks at room temperature. A full factorial design was used to test the effects of different freeze-thaw patterns (FTC, frozen and nonfrozen) 
and litter (remained vs. removed) on soil $\mathrm{N}$ mineralization. There were three temperature settings in triplicate that were controlled by different freezers and based on previously reported observational data and temperature dynamic characteristics ${ }^{21}$ : one set was subjected to 80 FTCs, where each FTC involved $12 \mathrm{~h}$ at $-5^{\circ} \mathrm{C}$ and $12 \mathrm{~h}$ at $5^{\circ} \mathrm{C}$ for a total of $24 \mathrm{~h}$ for each FTC; the other two sets were incubated at constant temperatures of $-5^{\circ} \mathrm{C}$ (frozen) or $5^{\circ} \mathrm{C}$ (nonfrozen). The litter-removal treatment involved only of soil sampling in the culture tanks; the other subsample was subjected to the litter-remained treatment, in which $1.63 \mathrm{~g}$ of air-dried leaf litter was added to the soil surface in accordance with the annual leaf production in $P$. purpurea forests ${ }^{39,42}$ and the surface area of the culture tank.

The culture tanks were weighed twice weekly to determine any weight loss (assumed to be due to water loss), and distilled water was sprayed evenly over the surface of the soils to compensate for any differences ${ }^{43}$. Duplicate tanks were destructively sampled after $0,5,10,20,40$, and 80 days; both the soil and leaf litter from the three culture tanks in the same freezer were mixed separately and then analyzed.

Chemical and physical analyses. The soil $\mathrm{pH}$ was determined using a $1 / 2.5 \mathrm{soil} /$ water mixture, and the soil bulk density and the water-holding capacity were determined by coring ${ }^{44}$. Soil and litter organic carbon (C) concentrations were determined using the dichromate oxidation-sulfate-ferrous titration method; soil and litter total $\mathrm{N}$ concentrations were determined by the macro-Kjeldahl method; and soil and litter total phosphorus (P) concentrations were determined by the acid melt-molybdenum stibium anticolor method ${ }^{44,45}$. The soil MBN was extracted with $0.5 \mathrm{~mol} \mathrm{~L}^{-1}$ potassium sulfate $\left(\mathrm{K}_{2} \mathrm{SO}_{4}\right)$, and the concentration was determined by the chloroform fumigation extraction method ${ }^{46}$. The soil inorganic $\mathrm{N}$ and dissolved total $\mathrm{N}$ (DTN) were extracted with 2 mol L${ }^{-1}$ potassium chloride $(\mathrm{KCl})$, and the $\mathrm{NH}_{4}{ }^{+}-\mathrm{N}$ concentration in the soil was measured colorimetrically by the indophenol method ${ }^{28}$. The soil $\mathrm{NO}_{3}{ }^{-}-\mathrm{N}$ concentration was determined by the dual-wavelength colorimetric method ${ }^{47}$, and the soil DTN concentration was measured via potassium persulfate (KPS) oxidation-UV spectrophotometry ${ }^{48}$.

The soil DON concentration was determined by the differences between the soil DTN and inorganic $\mathrm{N}$ (sum of $\mathrm{NH}_{4}{ }^{+}-\mathrm{N}$ and $\left.\mathrm{NO}_{3}{ }^{-}-\mathrm{N}\right)^{49}$. We define mineralizable $\mathrm{N}$ as the increase in inorganic $\mathrm{N}\left(\mathrm{NH}_{4}{ }^{+}-\mathrm{N}_{\text {and }} \mathrm{NO}_{3}{ }^{-}-\mathrm{N}\right)$ during 80 days of incubation.

Kinetic models for net $\mathbf{N}$ mineralization. The modified first-order exponential model (two-pool model) is expressed in the following form:

$$
\mathrm{N}_{\mathrm{m}}=\mathrm{N}_{\mathrm{e}}(1-\exp (-\mathrm{kt}))+\mathrm{N}_{0}(\exp (-\mathrm{kt}))
$$

where $\mathrm{N}_{\mathrm{m}}$ represents the cumulative $\mathrm{N}$ mineralization (CNM, $\mathrm{mg}$ of $\mathrm{N} \mathrm{kg}^{-1}$ soil); $\mathrm{N}_{\mathrm{e}}$, the microbial biomass $\mathrm{N}$ ( $\mathrm{mg}$ of $\mathrm{N} \mathrm{kg}^{-1}$ soil); $\mathrm{N}_{0}$, the potentially mineralizable $\mathrm{N}$ ( $\mathrm{mg}$ of $\mathrm{N} \mathrm{kg}^{-1}$ soil); and $\mathrm{k}$, the mineralization constant (or mineralization), which is expressed in days ${ }^{-1}$ because the incubation time $(t)$ is expressed in days.

Calculations and statistical analysis. Soil $\mathrm{N}$ pools and $\mathrm{N}$ fluxes under different freeze-thaw patterns in the same litter treatment during the same incubation period were calculated using one-way analysis of variance (ANOVA). Three-way repeated measures ANOVA on all three factors test was used to evaluate the effects of the freeze-thaw treatment, litter treatment, incubation duration and their interactions on the indices of the soil $\mathrm{N}$ pools and $\mathrm{N}$ fluxes. On the basis of the fitting analyses of the different $\mathrm{N}$ mineralization model $\mathrm{s}^{50}$, three models, including the single first-order exponential model ${ }^{51}$, the modified first-order exponential model (two-pool model $)^{37}$ and the mixed first and zero-order model ${ }^{52}$, were established to test $\mathrm{N}$ mineralization in the soils throughout the incubation period. Furthermore, the modified first-order exponential model (two-pool model) was selected to further obtain the mineralization parameter among treatments according to the lowest finite Akaike information criterion (AIC). Moreover, Tukey's test was performed to evaluate the parameters among treatments. In addition, stepwise regression analysis was conducted to examine the main soil $\mathrm{N}$ pool factors that determine the soil CNM under different treatments, and the best general linear model was developed according to the lowest finite AIC. R software (version 3.4.3) was used to construct point plots and to perform ANOVAs, Tukey's tests and stepwise regressions, and exponential regression and model selection were constructed and performed using Origin (version 9.0), respectively.

\section{References}

1. Attiwill, P. M. \& Adams, M. A. Tansley review no. 50. nutrient cycling in forests. New Phytol. 124, 561-582 (1993).

2. Waring, B. G., Adams, R., Branco, S. \& Powers, J. S. Scale-dependent variation in nitrogen cycling and soil fungal communities along gradients of forest composition and age in regenerating tropical dry forests. New Phytol. 209, 845-854 (2016).

3. Geisseler, D., Horwath, W. R., Joergensen, R. G. \& Ludwig, B. Pathways of nitrogen utilization by soil microorganisms-A review. Soil Biol. Biochem. 42, 2058-2067 (2010).

4. Osterholz, W. R. et al. Predicting gross nitrogen mineralization and potentially mineralizable nitrogen using soil organic matter properties. Soil Sci. Soc. Am. J 81, 1115-1126 (2017).

5. Vitousek, P. M. \& Sanford, R. L. Nutrient cycling in moist tropical forest. Annu. Rev. Eco. S 17, 137-167 (1986).

6. Yue, K. et al. Assessing the temporal dynamics of aquatic and terrestrial litter decomposition in an alpine forest. Functional Ecology. 00, 1-12 (2018).

7. Inagaki, Y., Miura, S. \& Kohzu, A. Effects of forest type and stand age on litterfall quality and soil N dynamics in Shikoku district, southern Japan. Forest Ecol. Manag. 202, 107-117 (2004).

8. Song, Q. N. et al. Degradation of litter quality and decline of soil nitrogen mineralization after moso bamboo (Phyllostachys pubscens) expansion to neighboring broadleaved forest in subtropical China. Plant \& Soil 404, 113-124 (2016).

9. Bowman, W. D., Steltzer, H., Rosenstiel, T. N., Cleveland, C. C. \& Meier, C. L. Litter effects of two cooccurring alpine species on plant growth, microbial activity and immobilization of nitrogen. Oikos 104, 336-344 (2004).

10. Gao, D. et al. Responses of terrestrial nitrogen pools and dynamics to different patterns of freeze-thaw cycle: A meta-analysis. Global Change Biol 00, 1-13 (2017). 
11. Song, Y., Zou, Y., Wang, G. \& Yu, X. Altered soil carbon and nitrogen cycles due to the freeze-thaw effect: A meta-analysis. Soil Biol. Biochem. 109, 35-49 (2017).

12. Bai, E. et al. A meta-analysis of experimental warming effects on terrestrial nitrogen pools and dynamics. New Phytol. 199, 441-451 (2013).

13. Jiang, L. P., Yue, K., Yang, Y. L. \& Wu, Q. G. Leaching and freeze-thaw events contribute to litter decomposition - A review. Sains Malays. 45, 1041-1047 (2016).

14. Amin, M. M. Microbial communities and their characteristics in a soil amended by nanozeolite and some plant residues: Short time in-situ incubation. Eurasian Soil Sci 7, 9-19 (2018).

15. Moran, K. K., Six, J., Horwath, W. R. \& Van Kessel, C. Role of mineral-nitrogen in residue decomposition and stable soil organic matter formation. Soil Sci. Soc. Am. J 69, 1730-1736 (2005).

16. Mooshammer, M. et al. Adjustment of microbial nitrogen use efficiency to carbon:nitrogen imbalances regulates soil nitrogen cycling. Nat. Commun. 5, 1-7 (2014).

17. Prevost-Boure, N. C. et al. Seasonal dynamics of the bacterial community in forest soils under different quantities of leaf litter. Appl. Soil Ecol. 47, 14-23 (2011).

18. Brant, J. B., Sulzman, E. W. \& Myrold, D. D. Microbial community utilization of added carbon substrates in response to long-term carbon input manipulation. Soil Biol. Biochem. 38, 2219-2232 (2006).

19. Schimel, J. P. \& Clein, J. S. Microbial response to freeze-thaw cycles in tundra and taiga soils. Soil Biol. Biochem. 28, 1061-1066 (1996).

20. Nielsen, C. B. et al. Freezing effects on carbon and nitrogen cycling in northern hardwood forest soils. Soil Sci. Soc. Am. J 65, $1723-1730$ (2001).

21. Zhu, J., He, X., Wu, F., Yang, W. \& Tan, B. Decomposition of litter varies with freeze-thaw stages and altitudes in subalpine/alpine forests of southwest China. Scand. J. Forest Res. 27, 586-596 (2012).

22. Wu, F. Z., Yang, W. Q., Zhang, J. \& Deng, R. J. Litter decomposition in two subalpine forests during the freeze-thaw season. Acta Oecol. 36, 135-140 (2010).

23. Larsen, K. S., Jonasson, S. \& Michelsen, A. Repeated freeze-thaw cycles and their effects on biological processes in two arctic ecosystem types. Appl. Soil Ecol. 21, 187-195 (2002).

24. Siirapietikainen, A., Haimi, J., Kanninen, A., Pietikainen, J. \& Fritze, H. Responses of decomposer community to root-isolation and addition of slash. Soil Biol. Biochem. 33, 1993-2004 (2001).

25. Feng, X., Nielsen, L. L. \& Simpson, M. J. Responses of soil organic matter and microorganisms to freeze-thaw cycles. Soil Biol. Biochem. 39, 2027-2037 (2007).

26. Campbell, J. L., Reinmann, A. B. \& Templer, P. H. Soil freezing effects on sources of nitrogen and carbon leached during snowmelt. Soil Sci. Soc. Am. J 78, 297-308 (2014).

27. Buckeridge, K. M., Cen, Y. P., Layzell, D. B. \& Grogan, P. Soil biogeochemistry during the early spring in low arctic mesic tundra and the impacts of deepened snow and enhanced nitrogen availability. Biogeochemistry 99, 127-141 (2010).

28. Tan, B., Wu, F. Z., Yang, W. Q., Wang, A. \& Yang, Y. L. Soil biochemical dynamics at three elevations during the soil thawing period, Eastern Tibetan Plateau: Nutrient availabilities, microbial properties and enzyme activities. Afr. J. Microbiol. Res. 6, 4712-4721 (2012).

29. Sorensen, P. O. et al. Winter soil freeze-thaw cycles lead to reductions in soil microbial biomass and activity not compensated for by soil warming. Soil Biol. Biochem. 116, 39-47 (2018).

30. Sulkava, P. \& Huhta, V. Effects of hard frost and freeze-thaw cycles on decomposer communities and $\mathrm{N}$ mineralisation in boreal forest soil. Applied Soil Ecology 22, 225-239 (2003).

31. Campbell, J. L., Socci, A. M. \& Templer, P. H. Increased nitrogen leaching following soil freezing is due to decreased root uptake in a northern hardwood forest. Global Change Biology 20, 2663-2673 (2014).

32. Vestgarden, L. S. \& Austnes, K. Effects of freeze-thaw on C and N release from soils below different vegetation in a montane system: a laboratory experiment. Global Change Biology 15, 876-887 (2010).

33. Cotrufo, M. F. et al. Formation of soil organic matter via biochemical and physical pathways of litter mass loss. Nature Geoscience 8 , 776-779 (2015).

34. Jones, D. L., Shannon, D., Murphy, D. V. \& Farrar, J. Role of dissolved organic nitrogen (DON) in soil N cycling in grassland soils. Soil Biology \& Biochemistry 36, 749-756 (2004).

35. Zhou, J. L. et al. Estimating the kinetic parameters of soil organic nitrogen mineralization for various land use types in a typicalhilly red-soil region in subtropical central China. Research of Agricultural Moder 36, 702-707 (2015).

36. Lindemann, W. C. \& Cardenas, M. Nitrogen mineralization potential and nitrogen transformations of sludgeamended soil. Soil Sci. Soc. Am. J 48, 1072-1077 (1984).

37. Beauchamp, E. G., Reynolds, W. D., Braschevilleneuve, D. \& Kirby, K. Nitrogen mineralization kinetics with different soil pretreatments and cropping histories 1. Soil Sci. Soc. Am. J 50, 1478-1483 (1986).

38. Li, C. et al. The relationship between community structure of ground-dwelling vertebrates and habitat types in the Wanglang Natural Reserve. Acta Ecologica Sinica 37, 4247-4257 (2017).

39. Yang, W. Q. et al. Annual and monthly variations in litter macronutrients of three subalpine forests in Western China. Pedosphere 16, 788-798 (2006).

40. Group, C. S. S. C. R. China soil system classification (amendment scheme). Agricultural science and technology press of China, Beijing (1995).

41. Gong, Z. T. et al. Pedgenesis and soil taxonomy. Science press of China, Beijing (2007).

42. Fu, C. K. et al. Seasonal Dynamics of Litterfall in a sub-alpine spruce-fir forest on the Eastern Tibetan Plateau: Allometric scaling relationships based on one year of observations. Forests 8, 314 (2017).

43. Guntiñasaaba, M. E. Effects of moisture and temperature on net soil nitrogen mineralization: A laboratory study. European Journal of Soil Biology 48, 73-80 (2012).

44. Zhang, W. Y. et al. Forest industry standard of the people's republic of China-forest soil analysis method. Standards Press of China, Beijing (2000).

45. Dong, M. Survey, observation and analysis of terrestrial biodiversities. Standards Press of China, Beijing (1997).

46. Inglett, P. W. \& Inglett, K. S. Biogeochemical changes during early development of restored calcareous;wetland soils. Geoderma 192, 132-141 (2013)

47. Bosch Ojeda, C. \& Sanchez Rojas, F. Recent developments in derivative ultraviolet/visible absorption spectrophotometry. Analytica Chimica Acta 518, 1-24 (2004).

48. Zheng, J. P. Discussion on the improvement of determination of total-nitrogen in water by potassium persulfate oxidation-UV spectrophotometry. Chinese. Journal of Spectroscopy Laboratory 28, 210-217 (2011)

49. Chen, C. R., Xu, Z. H., Zhang, S. L. \& Keay, P. Soluble organic nitrogen pools in forest soils of subtropical Australia. Plant \& Soil 277, 285-297 (2005).

50. Wang, X. X. et al. Kinetics modeling of soil nitrogen mineralization: A review. World Sci-Tech R \& D 39, 164-173 (2017).

51. Stanford, G. \& Smith, S. J. Nitrogen mineralization potentials of soils. Soil Sci. Soc. Am. J36, 465-472 (1972).

52. Bonde, T. A. \& Rosswall, T. Seasonal variation of potentially mineralizable nitrogen in four cropping systems 1. Soil Sci. Soc. Am. J 51, 1508-1514 (1987). 


\title{
Acknowledgements
}

This work was supported by the National Key R\&D Program of China (2017YFC0505003 and 2017YFC0503906), the National Natural Science Foundation of China (31622018, 31670526, 31570445 and 31700542) and the Fok Ying Tong Educational Foundation (161101).

\section{Author Contributions}

Fuzhong $\mathrm{Wu}$ and Wanqin Yang conceived the idea for the study, and Fuzhong Wu, Wanqin Yang, Bo Tan and Li Zhang designed the experiment. Yulian Yang, Xinyu Wei, Ya Chen and Kai Yue performed the research, and Yulian Yang, Xiangyin Ni, Xinyu Wei, and Ya Chen analyzed the data. Fuzhong Wu proposed the structure of the paper, and Yulian Yang wrote the paper.

\section{Additional Information}

Competing Interests: The authors declare no competing interests.

Publisher's note: Springer Nature remains neutral with regard to jurisdictional claims in published maps and institutional affiliations.

\begin{abstract}
(c) (1) Open Access This article is licensed under a Creative Commons Attribution 4.0 International License, which permits use, sharing, adaptation, distribution and reproduction in any medium or format, as long as you give appropriate credit to the original author(s) and the source, provide a link to the Creative Commons license, and indicate if changes were made. The images or other third party material in this article are included in the article's Creative Commons license, unless indicated otherwise in a credit line to the material. If material is not included in the article's Creative Commons license and your intended use is not permitted by statutory regulation or exceeds the permitted use, you will need to obtain permission directly from the copyright holder. To view a copy of this license, visit http://creativecommons.org/licenses/by/4.0/.
\end{abstract}

(c) The Author(s) 2019 